\title{
Extrusion Process Optimization of Corn Starch to Develop Instant Vegetable Soup Mix
}

\author{
Neeraj Gandhi", Baljit Singh, Savita Sharma and Swati Kapoor \\ Department of Food Science and Technology, Punjab Agricultural University, \\ Ludhiana-141004, Punjab, India \\ *Corresponding author
}

\section{A B S T R A C T}

This study was carried out to explore the possibility of using extrusion technology to produce instant vegetable soup mixes from corn starch. Response surface methodology

\section{Keywords}

Extrusion, Starch, Corn, Response surface methodology, Soup mixes

Article Info

Accepted:

26 January 2018

Available Online:

10 February 2018 was used to analyze the effect of feed moisture $(14-18 \%)$, barrel temperature $\left(125-175^{\circ} \mathrm{C}\right)$ and screw speed (400-550 rpm) on quality responses (specific mechanical energy, bulk density, expansion ratio, water absorption index, water solubility index, degree of gelatinisation and in-vitro starch digestibility) and regression analysis was carried out to fit mathematical models to the experimental data. All the processing conditions had significant influence on the extruded corn starch. Optimization results indicated that feed moisture of $16.13-18 \%$, screw speed of 400-429 and 539-550 rpm and barrel temperature of $125-137^{\circ} \mathrm{C}$ would produce modified corn starch of preferable functional properties. Instant vegetable soup mix powder was prepared by blending optimised extruded corn starch $50 \%$, dried vegetable powder $17.9 \%$, skim milk powder $10 \%$, sugar $10 \%$, salt $10 \%$, black pepper $2 \%$ and citric acid $0.1 \%(\mathrm{w} / \mathrm{w})$. The developed instant soup mixes have high degree of starch gelatinization, digestibility and acceptability. Soup mixes contain high protein and less fat as compare to commercial products. It is concluded that high quality instant vegetable soup mixes can be developed using extrusion technology.

\section{Introduction}

Instant foods are convenient food products that are easy and quick to prepare besides being hygienic, free from microbial contamination (Tamlurkar, 2006). The instant food market is observing a growth rate of around 12-15 per cent globally. Soups are generally consumed for health as well as nutritive benefits particularly in patients whose intake of solids is poor due to several obstructive or pathological reasons. Instant soups are a group of dried foods which play an important role in the nutrition of people because they fulfill present and future social consumer requirements (Kanias, 1991). These are available in the form of dry granules, dry compacted cubes or as a concentrated liquid which when prepared for eating is diluted with water to the desired concentration. Dry soup mixes, due to their long storage life at ordinary temperatures and their low unit 
volume, are well adapted to institutional use as well as to military rations. Apart from good storage stability of these products, the products with nutritional/therapeutic properties will be well received all over the world because of the increasing health consciousness amongst the population. Commercial instant soups based on corn, chicken, mixed vegetables, palak, mushroom etc. are common in most countries. But there are many drawbacks associated with these products such as heating for several minutes, lump formation, poor dispersion/ hydration, deficiency in taste, added artificial colour/ flavour, high costs of raw materials and lack of proper processing technologies and instant soup mixes of good quality remain out of reach of the general population. Various studies have been done to develop instant soup (Adegoke et al., 2016; Karthikeyan et al., 2015, Abdel-Haleem and Omran, 2014; Sudharani et al., 2013) using different ingredients such as pepper, banana peel, legumes, ash gourd-aonla etc and many patents have issued that described the attempts made to develop rapidly soluble soups. While the findings of these studies and other patents are of interest to food technologists but still the instant soup products which are available to the public are not all that could be desired.

Extrusion technology has been frequently used by industries to make the variety of instant starch based extruded products with low cost and high efficiency. Extrusion cooking is a high-temperature short-time (HTST) process which uses a combination of temperature, pressure, and shear force to convert the moistened starchy and proteinaceous raw materials into highly expanded, low-density products with unique physicochemical properties (Singh et al., 2015). Advantages of extrusion process include improving digestibility by gelatinisation of starch, denaturation of proteins and inactivation of antinutritional factors. Moreover, the high temperature applied during extrusion cooking ensures hygienic quality. The degradation of food nutrients through extrusion process was minimised due to the short time of heating treatment (Singh et al., 2014).

Starch contributes greatly to the textural properties of many foods and has many industrial applications as a thickener, colloidal stabilizer, gelling agent, bulking agent, water retention agent and adhesive. Much of industrial starch is processed or modified to increase its dissolution in water, to decrease gel viscosity and minimize retrogradation tendency of amylose. Extrusion cooking has been successfully used for modification of starch (Kaur et al., 2013). The use of such modified corn starch in soup mix formulation ensured reduction in the pasting viscosities, improved its ability to hold more quantities of solids, and nutrient density. Extruded flour/starch only requires reconstitution in warm water before consumption (Onyango et $a l ., 2004)$, so can be used for preparation of powdered instant soup mix. Incorporation of antioxidant-rich ingredients such as tomatoes and mushrooms into soup will further add variety, provide health benefits and make food appetizing. Several other ingredients such as skim milk powder, sugar, salt have been used in the study to prepare acceptable soup mixes.

Therefore, efforts have been made for the development of low cost instant soup mix using HTST processing. The study was attempted using RSM (response surface methodology). The use of RSM helps in unbiased development of the product and better optimization of the ingredients for the desired responses. This approach has been used by several researches (Wadikar et al., 2008; 2011; Pandey et al., 2009) in recent decade for product/process development. The objective of this work was to determine the optimum combination of extrusion conditions for the production of modified corn starch to 
develop instant vegetable soup mix using a twin-screw extruder.

\section{Materials and Methods}

\section{Raw materials and proximate analysis}

Corn starch (Weik field) was procured from the local market, Ludhiana, Punjab. Skim milk powder (protein 18.7\%, fat $18.9 \%$ and carbohydrates 55.2\%), fresh tomatoes (commonly cultivated variety; moisture $94.3 \%$, protein $0.9 \%$, fat $0.2 \%$, fibre $0.8 \%$, carbohydrates $3.6 \%$ ), fresh mushrooms (oyster; moisture $88.5 \%$, protein $3.0 \%$, fat $0.8 \%$, fibre $0.4 \%$, carbohydrates $4.3 \%$ ), powdered sugar (purity 97\%), salt, black pepper and citric acid were procured from local market. Tomatoes and mushrooms were dried using standard procedures and ground to powder. Proximate analysis of raw materials and instant soup mixes was determined by the standard method of AOAC (2006). Moisture content was estimated by direct oven-drying method; crude protein was determined by multiplying the total nitrogen obtained from micro-Kjeldahl method by a factor of 6.25; fat was estimated by Soxhlet extraction method (using Soxtec TM 2045, Foss Instruments, Hoganas, Sweden); crude fibre was determined by Weende method (using FC 221 FiberCapTM, Foss Instruments, Hilleroed, Denmark); ash was measured gravimetrically after ashing at $550{ }^{\circ} \mathrm{C}$, and carbohydrates were calculated by the difference. The proximate analysis of the corn starch was $8.59 \%$ moisture, $0.40 \%$ crude protein, $0.10 \%$ fat, $2.03 \%$ crude fibre, $0.18 \%$ ash and $88 \%$ carbohydrates.

\section{Experimental design}

The effects of extrusion conditions on the product responses were studied while screw configuration was kept constant. Feed rate was varied from 14 to $24 \mathrm{~kg} / \mathrm{h}$ for optimum filling of the extruder barrel corresponding to the screw speed. The water pump and feed rate were thoroughly calibrated before conducting the experiments. Based on the calibration, the calculated amount of water was added for each run taking into consideration the feed rate and the moisture content of raw materials for particular run. RSM with five levels CCRD with three independent variables, eight factorial points, six axial points, six central points and twenty experimental runs was used. Independent variables considered in this study were feed moisture (14-18\%), screw speed (400-550 rpm) and barrel temperature (125$\left.175{ }^{\circ} \mathrm{C}\right)$, while dependent variables were specific mechanical energy (SME), bulk density (BD), expansion ratio (ER), water absorption index (WAI), water solubility index (WSI), degree of gelatinisation (DG) and in vitro starch digestibility (SD). The levels of extrusion conditions were established based on preliminary trials. The obtained data were used to determine the optimum extrusion processing conditions of corn starch extrudates by optimization tools given in the software package (Design- Expert, version 7, Stat-Ease, Inc., Minneapolis, MN, USA).

\section{Extrusion process}

Extrusion experiments were carried out using a laboratory- scale co-rotating and intermeshing twin-screw extruder (Model BC 21, Clextral, Firminy, France) (Figure 1a). The screws of the extruder were $25 \mathrm{~mm}$ in diameter and $400 \mathrm{~mm}$ in length (Figure 1b).

The extruder barrel which contains screws was divided into four zones; the temperature of the first, second and third zone during extrusion cooking was maintained at 40,70 and $100{ }^{\circ} \mathrm{C}$, respectively, while the temperature of the fourth zone was varied according to each run of experimental design. The die has four openings with diameter of $1.5 \mathrm{~mm}$ for each; extrudates were cut by controlled speed cutter 
with four bladed knives attached with the die. Extruder was powered by 8.5 kilowatt motor with speed variable from 0 to $682 \mathrm{rpm}$. A single-screw volumetric feeder (D.S. and M, Modena, Italy) was utilised to adjust the feeding rate of the corn starch. Feed moisture was controlled by injecting the water by a built-in water pump attached with the extruder.

\section{Product responses}

\section{Specific mechanical energy (SME)}

Specific mechanical energy (Wh/kg) was calculated from the values of actual screw speed, rated screw speed $(682 \mathrm{rpm})$, motor torque $(\%)$, rated motor power $(8.5 \mathrm{~kW})$ and mass flow rate according to the method described by Singh et al., (2015).

SME $(\mathrm{Wh} / \mathrm{kg})=($ Actual screw speed $(\mathrm{rpm}) /$ Rated screw speed (rpm)) x (Per cent motor torque / 100) x (Motor power rating / Mass flow rate $(\mathrm{kg} / \mathrm{h})) \times 1000$

\section{Bulk density (BD)}

The Bulk density $(\mathrm{g} / \mathrm{cc})$ of extruded starch was measured by using a $100 \mathrm{ml}$ graduated cylinder by rapeseed displacement and gently tapped for 5 times. The volume of $20 \mathrm{~g}$ randomized samples was measured for each test. The ratio of sample weight and the replaced volume in the cylinder was calculated as bulk density (Patil et al., 2007).

Weight of extrudates $\mathrm{x} 1000$ Bulk Density $(\mathrm{g} / \mathrm{cc})=----------------------$ Volume displaced by extrudates

\section{Expansion Ratio}

The expansion ratio was calculated by average diameter of corn extrudates divided by die diameter (1.5mm) (Anton et al., 2009).
Water absorption index (WAI) and water solubility index (WSI)

The WAI and WSI were determined by following the method developed by Yagci and Gogus (2008). The ground starch extrudates were suspended in $30 \mathrm{~mL}$ of distilled water at room temperature for $30 \mathrm{~min}$, gently stirred during this period and then centrifuged at $3000 \mathrm{x} \mathrm{g}$ for $15 \mathrm{~min}$. The supernatant was poured into an evaporating dish of known weight and put in the oven at $110{ }^{\circ} \mathrm{C}$ till constant weight. The WAI was the weight of gel obtained after removal of the supernatant per unit weight of original extruded sample. The WSI was the weight of dry solids in the supernatant after evaporation and expressed as a percentage of the original weight of sample.

WAI $(\mathrm{g} / \mathrm{g})=\frac{\text { Weight of sediment }}{\text { Weight of extruded sample }}$

Weight of dissolved solid in supernatant WSI $(\%)=$

Weight of extruded sample

\section{Degree of gelatinisation (DG)}

Degree of gelatinisation of extruded corn starch was determined by using amylose/iodine blue method (Cai and Diosady, 1993). To $0.2 \mathrm{~g}$ of ground sample, $98 \mathrm{~mL}$ of water was added and treated with 2 $\mathrm{ml} 10 \mathrm{M}-\mathrm{KOH}$ solution and agitated gently for $5 \mathrm{~min}$. The slurry was centrifuged and $1 \mathrm{ml}$ aliquot of the supernatant was mixed with $0.4 \mathrm{~mL}$ of $0.5 \mathrm{M} \mathrm{HCL}$ and made up to $10 \mathrm{ml}$ with water. $0.1 \mathrm{ml}$ of iodine reagent $(1 \mathrm{~g}$ iodine and $4 \mathrm{~g}$ potassium iodide per $100 \mathrm{ml}$ water) was then added and after mixing the absorbance $\left(\mathrm{A}_{1}\right)$ was read at $600 \mathrm{~nm}$ on Spectronic-200 against a reagent blank. The estimation was repeated using $95 \mathrm{ml}$ water and $5 \mathrm{ml} 10 \mathrm{M}-\mathrm{KOH}$ solution, and $1.0 \mathrm{ml} 0.5 \mathrm{M}-$ $\mathrm{HC} 1$ for neutralization and absorbance was 
recorded $\left(\mathrm{A}_{2}\right)$. The ratio of the two absorbance obtained from each sample was used to measure degree of gelatinization.

Degree of gelatinization $(\%)=\frac{\mathrm{A}_{1}}{-----} \times 100$

\section{In vitro starch digestibility (SD)}

In vitro starch digestibility of extruded corn starch was determined by estimating the quantity of maltose formed by the dinitrosalicylic acid method of Bernfeld (1955). 100mg finely ground sample was dispersed in phosphate buffer $\mathrm{pH} 6.9$ and incubated with $100 \mathrm{mg} \alpha$-amylase at $37^{\circ} \mathrm{C}$ in a total volume of $20 \mathrm{ml}$ buffer. The rate of enzymatic hydrolysis of starch was determined by estimating the amount of maltose released upto a period of $2 \mathrm{~h}$. After the filtration, $2 \mathrm{ml}$ of dinitrisalicylic acid was added to tube (containing $1 \mathrm{ml}$ filterate) to arrest the reaction, boiled for $5 \mathrm{~min}$, cooled and made volume to $50 \mathrm{ml}$.

Absorbance was read at $540 \mathrm{~nm}$, standard curve of maltose was used to calculate $\mathrm{mg}$ of maltose released corresponding to absorbance of sample.

\section{Statistical analysis}

Statistical software (Design-Expert, version 7, Stat-Ease, Inc., Minneapolis, MN, USA) was employed to model the behaviour of the responses (SME, BD, ER, WAI, WSI, DG and $\mathrm{SD})$ as a function of the processing variables (feed moisture, screw speed and barrel temperature) using RSM. Second-order polynomial regression models were established to fit experimental data for each response. The equation was as follows:

$\mathrm{Y}_{\mathrm{i}}=\mathrm{b}_{0} \pm \mathrm{b}_{1} \mathrm{~A} \pm \mathrm{b}_{2} \mathrm{~B} \pm \mathrm{b}_{3} \mathrm{C} \pm \mathrm{b}_{12} \mathrm{AB} \pm \mathrm{b}_{13} \mathrm{AC} \pm$ $b_{23} B C \pm b_{11} A^{2} \pm b_{22} B^{2} \pm b_{33} C^{2}$
Where $\mathrm{Y}_{\mathrm{i}}$ was the predicted response. Coefficients were represented by $b_{0}$ as intercept; $b_{1}, b_{2}, b_{3}$ as linear effects; $b_{12}, b_{13}$, $b_{23}$ as interaction effects; and $b_{11}, b_{22}, b_{33}$ as quadratic effects. Independent variables (feed moisture, screw speed and barrel temperature) were symbolised as A, B and C, respectively. The developed models were validated by analysis of variance (ANOVA) where high $\mathrm{F}$ values and low $\mathrm{P}$-values of the developed models reveal more significant effect of the independent variables on the determined response (Yuan et al., 2008; Singh et al., 2015). Lack of fit, an indicator of model incompatibility, should be insignificant that indicates good correlation with the determined data. The coefficient of variation (CV) measures the relative dispersion of the experimental points from the predictions of the model. The lower the CV, the smaller the dispersion in the variable that reveals a good model fit; CV values $<10 \%$ are desirable. Coefficient of determination $\left(\mathrm{R}^{2}\right)$ determines the amount of variation around the mean and reveals the degree of fitness; $\mathrm{R}^{2}$ values close to one represent the best model fitness with the actual data. The predicted $\mathrm{R}^{2}$ should be close to the adjusted $\mathrm{R}^{2}$; the difference between both should be less than 0.2. Adequate precision estimates the signal-tonoise ratio; values of adequate precision higher than four are favourable (Banerjee $e t$ al., 2010).

\section{Optimization}

Optimization means the processing conditions that give the optimum (maximum or minimum) value of a function of certain decided variables subject to constraints that are imposed. Graphical optimization tools given in the Design-Expert software were employed to optimise extrusion processing conditions in order to obtain modified corn starch with acceptable properties. On the basis of organoleptic study, five samples of most 
acceptable functional characteristics were selected and their minimum and maximum range for each response was used for graphical optimization. SME was not included in optimization process as it is an operation parameter. Overlay contour plots were obtained by superimposing the contour plots of all responses to select the optimum combination of extrusion conditions for the final product.

Preparation of the instant vegetable soup mix

The optimised extrusion conditions were applied to extrude the modified corn starch. Extrudates were ground into powder form using laboratory-scale super mill and mixed with vegetable (tomato/ mushroom) powder, skim milk powder, sugar powder, salt, black pepper and citric acid using laboratory-scale ribbon blender. Extensive trials have been conducted to optimise the levels of ingredients for the final composition of the soup mix powder based on the product quality and scores of sensory attributes. Instant vegetable soup mix powder $(20 \mathrm{~g})$ was mixed with 200 $\mathrm{ml}$ of boiled water and served to trained panellists who were asked to rate the samples in terms of appearance, consistency, flavour and overall acceptability using nine-point hedonic scale (Balasubramanian et al., 2014).

\section{Results and Discussion}

\section{Model validation}

Based on ANOVA (Table 1), F-ratios for the designed models for all product responses (SME, BD, ER, WAI, WSI, DG and SD $(<10 \%)$, indicating that the designed models fit the data well for all variables. All developed models showed high coefficient of determination $\left(\mathrm{R}^{2}\right)$ that approaches unity except in-vitro starch digestibility $\left(\mathrm{R}^{2} 0.570\right)$. The predicted $\mathrm{R}^{2}$ was close to the adjusted $\mathrm{R}^{2}$ for all product responses. The designed models were accurate and suitable to investigate the actual correlation of product responses with the selected process parameters and experimental data. All product responses showed high adequate precision that indicates an adequate signal, and these models can be used to navigate the design space.

\section{Specific mechanical energy (SME)}

Specific mechanical energy (SME) gives the amount of mechanical energy delivers by the extruder to extrude material at particular set of condition like feed moisture content, screw speed and die temperature. The obtained values of SME during extrusion cooking of corn starch varied between 126.19 and 177.60 $\mathrm{Wh} / \mathrm{kg}$ (Table 2). The effect of extrusion variables on SME is shown in Figure 2a, b. The regression coefficients of linear effects of feed moisture and screw speed; and the quadratic effects of feed moisture, screw speed and barrel temperature for SME were significant $(\mathrm{P}<0.01)$ (Table 3). The feed moisture $\mathrm{x}$ barrel temperature interaction effect was also significant $(\mathrm{P}<0.05)$. The SME values similar to those observed for corn starch extrudates (Brummera et al., 2002). SME decreases with increasing feed moisture and barrel temperature and increases by increasing screw speed (Fig. 2a, b). Increasing the feed moisture during extrusion process creates a lubricating effect inside the extruder resulting in less energy consumption and consequently reduced SME (Singh et al., 2015). High barrel temperature leads to gelatinisation of starch that reduces the melt viscosity resulting in a decrease in SME (Guha et al., 1997). The higher the screw speed, the higher the SME input; increase in screw speed causes higher shearing and friction rates resulting in an increase in SME (Altan et al., 2008). Similar correlations of moisture, screw speed and temperature with SME have been reported by Gulati et al., 
(2016) in millet based extrudates, Singh et al., (2015) in potato based extrudates, Kaur et al., (2015) in corn extrudates, Pathania et al., (2013) in wheat, mung-bean and rice blend and Altan et al., (2008) in barley.

\section{Bulk density (BD)}

Bulk density ( $\mathrm{g} / \mathrm{lt}$ ) is defined as the ratio of the mass of extrudates to the apparent volume of a specific container. It is an important property of the final products from commercial point of view as it influences the required storage space either at the processing plant or during shipping (Guy, 2001). Bulk density has been linked with the expansion ratio in describing the degree of puffing in extrudates (Asare $e t$ $a l ., 2004)$. The measured BD of extruded corn starch ranged from 43.89 to $111.51 \mathrm{~g} / \mathrm{lt}$ (Table 2 ), with the lowest density recorded at the lowest feed moisture. The linear as well as quadratic regression coefficients of feed moisture, screw speed and barrel temperature for $\mathrm{BD}$ were significant $(\mathrm{P}<0.01)$, and the interactions of feed moisture with screw speed and temperature were also significant $(\mathrm{P}<$ 0.01) (Table 3). Feed moisture had strong positive relationship with $\mathrm{BD}$, whereas screw speed and barrel temperature had negative effect (Fig. 3a, b). Effects of extrusion conditions on BD were found to be comparable with the study reported by Hagenimana et al., (2006) and Meng et al., (2010) on rice and chickpea based extrudates. Increase in feed moisture during extrusion process would change the amylopectin networks in the starch-based materials that reduce elasticity characteristics of the dough through plasticisation of the melt resulting in reduced SME, reduced gelatinisation, decreased expansion and increased BD of extrudates (Ding et al., 2005). Moreover, high moisture creates a lubricating effect resulting in reduced SME, reduced the degradation of starch, reduced gelatinisation, decreased expansion and increased $\mathrm{BD}$ of extrudates
(Singh et al., 2015). The heat applied during extrusion would increase the temperature of the dough moisture above the boiling point; consequently, when extrudates exit the die, they suddenly transfer from high pressure inside the extruder to atmospheric pressure. This pressure drop causes a flash-off of internal moisture and improves bubble formation; bubbles are entrapped by the starch matrix resulting in a high expansion and lowdensity extrudates (Hagenimana et al., 2006; Altan et al., 2008). A decrease in bulk density at higher screw speed could be due to the development of high pressure generated by the revolving screw inside the barrel. Structural breakdown of protein and starch in the high shear environment also leads to low density of products (Lin et al., 2003).

\section{Expansion Ratio (ER)}

The expansion ratio describes the degree of puffing undergone by the material as it exits the extruder. Expansion ratio for corn starch extrudates varied from 3.02 to 5.57 (Table 2). The values in the current study were similar to that of corn starch extrudates study of Chinnaswamy and Hanna in 1990. The regression coefficients of linear and quadratic effects of feed moisture, screw speed and barrel temperature for ER were significant ( $P$ $<0.01$ ) (Table 3). The interaction effects of feed moisture $\mathrm{x}$ screw speed and screw speed $\mathrm{x}$ barrel temperature were also significant $(\mathrm{P}<$ $0.01)$. The effect of extrusion variables on ER is shown in Figure 4a, b. As feed moisture increased, ER showed a decreasing trend, while with increasing barrel temperature and screw speed ER increased. The increased expansion at high temperature could be a result of increased axial or longitudinal expansion as high temperature favors expansion in the axial direction (Ali et al., 1996). Therefore, precise control of extrusion condition is necessary to achieve desirable extrudate properties. On increasing 
temperature of barrel, starch gelatinization was more and resulted in higher expansion. Other studies also reported increased expansion with increased barrel temperature and reduced feed moisture content for corn grits and corn starch (Mercier and Feillet, 1975), rice flour (Ding et al., 2005). As the barrel temperature increased the viscosity of the feed material reduced, resulting in better expansion (Mercier and Feillet, 1975). Hagenimana et al., (2006) found that expansion ratio decreased with increasing feed moisture from 16 to $19 \%$ when rice flour was extruded in a twin screw extruder. Increasing screw speed and barrel temperature introduced more energy to the material in the barrel, which enhanced the moisture evaporation at the die exit and hence increases expansion ratio. Seker (2005) also found that increasing screw speed steadily enhanced expansion ratio. When the extrusion process was carried out at temperature above $100^{\circ} \mathrm{C}$, moisture gets superheated inside the extrusion barrel due to internal high temperature and high pressure conditions. As the product exits the die nozzle, moisture flash evaporates suddenly due to the pressure drop. As a result, the extruded product is expanded, and the characteristic texture of the extrudate is formed with a porous structure.

\section{Water absorption index (WAI)}

Water absorption index is the amount of water absorbed by the starch granules after swelling in excess water (Chevanan et al., 2007, Rodriguez-Miranda et al., 2011), which corresponds to the weight of the gel formed. The obtained values of WAI of extruded corn starch varied between 1.76 and $3.79 \mathrm{~g} / \mathrm{g}$ (Table 2). The regression coefficients for linear as well as quadratic effects of feed moisture, screw speed and barrel temperature for WAI were significant $(\mathrm{P}<0.01)$ (Table 3 ). The interaction effects of feed moisture $\mathrm{x}$ barrel temperature and screw speed $\mathrm{x}$ barrel temperature were also significant $(\mathrm{P}<0.01)$.
The WAI for corn starch extrudates was lower than extruded barley flour and rice based extruded snacks (Altan et al., 2008). As feed moisture and barrel temperature increased, WAI showed an increasing trend, while with increasing screw speed WAI decreased (Fig. $5 \mathrm{a}, \mathrm{b})$. Influence of extrusion conditions on WAI was in agreement with other researchers (Joshi et al., 2014; Singh et al., 2015). Water acts as a plasticiser during extrusion cooking that reduces the degradation of starch granules in the dough, thereby enhancing the capacity of water absorption by the starch, resulting in an increased WAI (Hagenimana et al., 2006; Suksomboon et al., 2011). A consistent increase in WAI with increase in temperature was reported by Kebede et al., (2010) for white tef extrudates. This increase was attributed to the higher proportion of gelatinized starch granules. Low WAI at lower temperature of extrusion indicated the restricted water availability for the starch granules, as they have a compact structure. However, when temperature increased, amylose and amylopectin chains form an expandable matrix that translated into a higher water retention capacity (Kokini et al., 1992). It is interesting to note that starch granules should reach a certain degree of conversion to achieve considerable water absorption. Low screw speed during extrusion process may reduce the damage of starch polymer and increase the availability of hydrophilic groups which can bind more water resulting in the increase of WAI values (Guha et al., 1997).

\section{Water solubility index (WSI)}

Water solubility index is basically used as an of degradation of molecular components, measures the degree of starch conversion during extrusion which corresponds to the amount of soluble polysaccharide released from the starch component after extrusion (Balasubramanian et al., 2014; Joshi et al.,2014). 
Table.1 Analysis of variance (ANOVA) for the fit of experimental data to response surface model

\begin{tabular}{|c|c|c|c|c|c|c|c|}
\hline Term & \multicolumn{5}{|c|}{ Product Responses } & & \\
\hline Factor & $\begin{array}{c}\text { SME } \\
(\mathrm{Wh} / \mathrm{Kg})\end{array}$ & $\begin{array}{l}\text { BD } \\
(\mathrm{g} / \mathrm{lt})\end{array}$ & ER & $\begin{array}{l}\text { WAI } \\
(\mathrm{g} / \mathrm{g})\end{array}$ & $\begin{array}{l}\text { WSI } \\
(\%)\end{array}$ & $\begin{array}{l}\mathrm{DG} \\
(\%)\end{array}$ & $\begin{array}{c}\text { SD } \\
(g / 100 g)\end{array}$ \\
\hline Model F value & $22.85^{*}$ & $243.41 *$ & $63.23 *$ & $62.89 *$ & $131.90 *$ & $325.50 *$ & $7.09 *$ \\
\hline Lack of fit & $1.39 * *$ & $1.69 * *$ & $1.76 * *$ & $2.86^{* *}$ & $1.84 * *$ & $0.64 * *$ & $0.97 * *$ \\
\hline C V (\%) & 2.95 & 2.85 & 3.32 & 4.03 & 1.87 & 2.04 & 4.16 \\
\hline $\mathbf{R}^{2}$ & 0.953 & 0.995 & 0.982 & 0.982 & 0.991 & 0.996 & 0.570 \\
\hline Adjusted $\mathbf{R}^{2}$ & 0.911 & 0.991 & 0.967 & 0.967 & 0.984 & 0.993 & 0.490 \\
\hline Predicted $\mathbf{R}^{2}$ & 0.767 & 0.975 & 0.901 & 0.895 & 0.954 & 0.986 & 0.394 \\
\hline $\begin{array}{l}\text { Adequate } \\
\text { precision }\end{array}$ & 13.34 & 51.92 & 23.44 & 28.23 & 38.16 & 45.01 & 9.65 \\
\hline
\end{tabular}

*Significant at $\mathrm{P}<0.01$, **non-significant at $\mathrm{P}>0.05$.

SME, specific mechanical energy; BD, bulk density; ER; expansion ratio; WAI, water absorption index; WSI, water solubility index; DG, degree of gelatinisation; $\mathrm{SD}$, in vitro starch digestibility)

Table.2 Experimental design and product responses obtained for the extrusion of corn starch

\begin{tabular}{|c|c|c|c|c|c|c|c|c|c|}
\hline \multicolumn{3}{|c|}{$\begin{array}{l}\text { Extrusion Conditions } \\
\text { (Actual and Coded values) }\end{array}$} & \multicolumn{7}{|c|}{ Product Responses } \\
\hline $\begin{array}{l}\text { A: Feed } \\
\text { moisture } \\
(\%)\end{array}$ & $\begin{array}{c}\text { B:Screw speed } \\
(\text { rpm })\end{array}$ & $\begin{array}{c}\text { C: Barrel } \\
\text { temperature } \\
\left({ }^{\circ} \mathbf{C}\right)\end{array}$ & $\begin{array}{c}\text { SME } \\
(w h / k g)\end{array}$ & $\begin{array}{l}\text { BD } \\
(\mathrm{g} / \mathrm{It})\end{array}$ & ER & $\begin{array}{l}\text { WAI } \\
(\mathrm{g} / \mathrm{g})\end{array}$ & $\begin{array}{l}\text { WSI } \\
(\%)\end{array}$ & $\begin{array}{l}\text { DG } \\
(\%)\end{array}$ & $\underset{(\mathrm{g} / \mathbf{1 0 0 g})}{\text { SD }}$ \\
\hline $14(-1)$ & $400(-1)$ & $125(-1)$ & 151.12 & 60.16 & 3.37 & 2.51 & 68.57 & 50.11 & 19.12 \\
\hline $18(1)$ & $400(-1)$ & $125(-1)$ & 126.19 & 91.21 & 3.19 & 3.74 & 47.12 & 59.99 & 20.96 \\
\hline $14(-1)$ & $550(1)$ & $125(-1)$ & 155.08 & 53.14 & 5.49 & 1.76 & 69.97 & 52.17 & 18.6 \\
\hline $18(1)$ & $550(1)$ & $125(-1)$ & 136.08 & 111.51 & 4.05 & 3.17 & 58.59 & 66.79 & 19.84 \\
\hline $14(-1)$ & $400(-1)$ & $175(1)$ & 144.07 & 72.17 & 4.69 & 2.55 & 74.51 & 67.57 & 20.88 \\
\hline $18(1)$ & $400(-1)$ & $175(1)$ & 138.65 & 72.26 & 4.23 & 3.12 & 51.21 & 66.55 & 22 \\
\hline 14(-1) & $550(1)$ & $175(1)$ & 151.12 & 43.89 & 5.45 & 2.58 & 68.51 & 56.57 & 18.84 \\
\hline $18(1)$ & $550(1)$ & $175(1)$ & 152.68 & 66.05 & 4.39 & 3.34 & 56.73 & 61.92 & 20.22 \\
\hline $\begin{array}{c}12.64(- \\
1.682)\end{array}$ & $475(0)$ & $150(0)$ & 168.26 & 46.36 & 5.57 & 2.01 & 78.18 & 48.48 & 19.44 \\
\hline $\begin{array}{c}19.36 \\
(+1.682)\end{array}$ & 475(0) & $150(0)$ & 149.56 & 86.88 & 3.84 & 3.79 & 51.04 & 65.69 & 20.82 \\
\hline $16(0)$ & $348.87(-1.682)$ & $150(0)$ & 130.31 & 70.94 & 4.04 & 3.02 & 66.97 & 55.89 & 20.36 \\
\hline $16(0)$ & $601.13(+1.682)$ & $150(0)$ & 151.48 & 58.15 & 5.5 & 2.44 & 70.73 & 53.13 & 18.36 \\
\hline $16(0)$ & $475(0)$ & $107.96(-1.682)$ & 146.08 & 91.4 & 3.02 & 2.39 & 48.18 & 71.18 & 17.8 \\
\hline $16(0)$ & $475(0)$ & $192.04(+1.682)$ & 135 & 64.34 & 4.51 & 3.06 & 55.76 & 81.41 & 20.52 \\
\hline $16(0)$ & $475(0)$ & $150(0)$ & 170.59 & 46.52 & 5.34 & 2.18 & 70.81 & 96.94 & 20.8 \\
\hline $16(0)$ & $475(0)$ & $150(0)$ & 165.14 & 47.84 & 5.52 & 2.3 & 72.05 & 97.97 & 21.91 \\
\hline $16(0)$ & $475(0)$ & $150(0)$ & 168.26 & 45.2 & 5.23 & 2.06 & 69.57 & 95.91 & 19.69 \\
\hline $16(0)$ & $475(0)$ & $150(0)$ & 171.37 & 48.6 & 5.28 & 2.19 & 71.82 & 97.88 & 21.53 \\
\hline $16(0)$ & $475(0)$ & $150(0)$ & 177.6 & 44.44 & 5.2 & 2.17 & 69.8 & 96 & 20.07 \\
\hline $16(0)$ & $475(0)$ & $150(0)$ & 170.57 & 46.55 & 5.48 & 2.18 & 70.82 & 93.62 & 21.05 \\
\hline
\end{tabular}

SME, specific mechanical energy; BD, bulk density; ER, expansion ratio; WAI, water absorption index; WSI, water solubility index; DG, degree of gelatinisation. 
Table.3 Regression coefficients for each response surface equation and model fit parameters

\begin{tabular}{|l|c|c|c|c|c|c|c|}
\multicolumn{1}{|c|}{ Parameter } & $\begin{array}{c}\text { SME } \\
(\mathrm{wh} / \mathrm{kg})\end{array}$ & $\begin{array}{c}\text { BD } \\
(\mathrm{g} / \mathrm{lt})\end{array}$ & ER & $\begin{array}{c}\text { WAI } \\
(\mathrm{g} / \mathrm{g})\end{array}$ & $\begin{array}{c}\text { WSI } \\
(\%)\end{array}$ & $\begin{array}{c}\text { DG } \\
(\%)\end{array}$ & $\begin{array}{c}\text { SD } \\
(\mathrm{g} / 100 \mathrm{~g})\end{array}$ \\
\hline Intercept of model & $170.62^{* *}$ & $46.52^{* *}$ & $5.34^{* *}$ & $2.18^{* *}$ & $70.79^{* *}$ & $96.40^{* *}$ & $20.14^{* *}$ \\
\hline Feed moisture (A) & $-5.80^{* *}$ & $13.17^{* *}$ & $-0.44^{* *}$ & $0.51^{* *}$ & $-8.31^{* *}$ & $4.23^{* *}$ & $0.58^{*}$ \\
\hline Screw speed (B) & $5.16^{* *}$ & $-3.13^{* *}$ & $0.47^{* *}$ & $-0.15^{* *}$ & $1.37^{* *}$ & -0.84 & $-0.65^{*}$ \\
\hline Barrel temperature (C) & -0.043 & $-7.85^{* *}$ & $0.38^{* *}$ & $0.11^{* *}$ & $1.42^{* *}$ & $2.98^{* *}$ & $0.59^{*}$ \\
\hline Feed moisture x Screw speed (AB) & 1.61 & $6.17^{* *}$ & $-0.23^{* *}$ & 0.046 & $2.70^{* *}$ & $1.39^{* *}$ & - \\
\hline Feed moisture x Barrel Temperature (AC) & $5.01^{*}$ & $-8.40^{* *}$ & 0.012 & $-0.16^{* *}$ & -0.28 & $-2.52^{* *}$ & - \\
\hline Screw speed x Barrel Temperature (BC) & 0.90 & $-5.97^{* *}$ & $-0.26^{* *}$ & $0.20^{* *}$ & $-1.67 * *$ & $-3.06^{* *}$ & - \\
\hline Feed moisture x Feed moisture $\left(\mathbf{A}^{2}\right)$ & $-4.33^{* *}$ & $7.15^{* *}$ & $-0.22^{* *}$ & $0.26^{* *}$ & $-2.06^{* *}$ & $-13.97^{* *}$ & - \\
\hline Screw speed x Screw speed $\left(\mathbf{B}^{2}\right)$ & $-10.70^{* *}$ & $6.42^{* *}$ & $-0.20^{* *}$ & $0.20^{* *}$ & -0.56 & $-14.88^{* *}$ & - \\
\hline Barrel Temperature $x$ Barrel Temperature $\left(\mathbf{C}^{2}\right)$ & $-10.83^{* *}$ & $11.13^{* *}$ & $-0.56^{* *}$ & $0.20^{* *}$ & $-6.53^{* *}$ & $-7.18^{* *}$ & - \\
\hline
\end{tabular}

$* *$ Significant at $\mathrm{P}<0.01$.

*Significant at $\mathrm{P}<0.05$.

SME, specific mechanical energy; BD, bulk density; ER, expansion ratio; WAI, water absorption index; WSI, water solubility index; DG, degree of gelatinisation; SD, in vitro starch digestibility.

Fig.1 (a) Clextral co-rotating intermeshing twin-screw extruder (model BC21); (b) Screw Profile
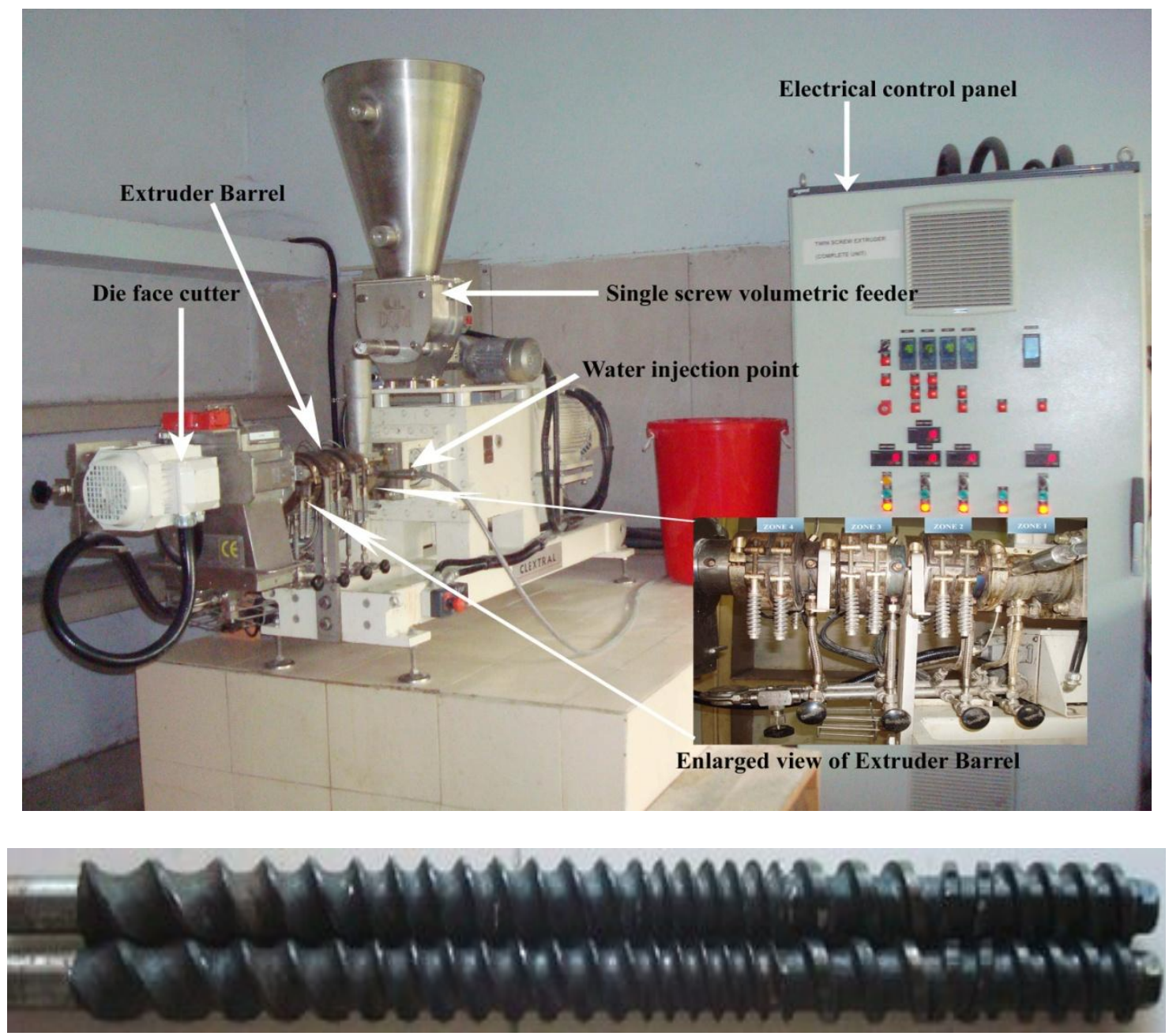
Fig.2 a, b Effect of extrusion variables on specific mechanical energy
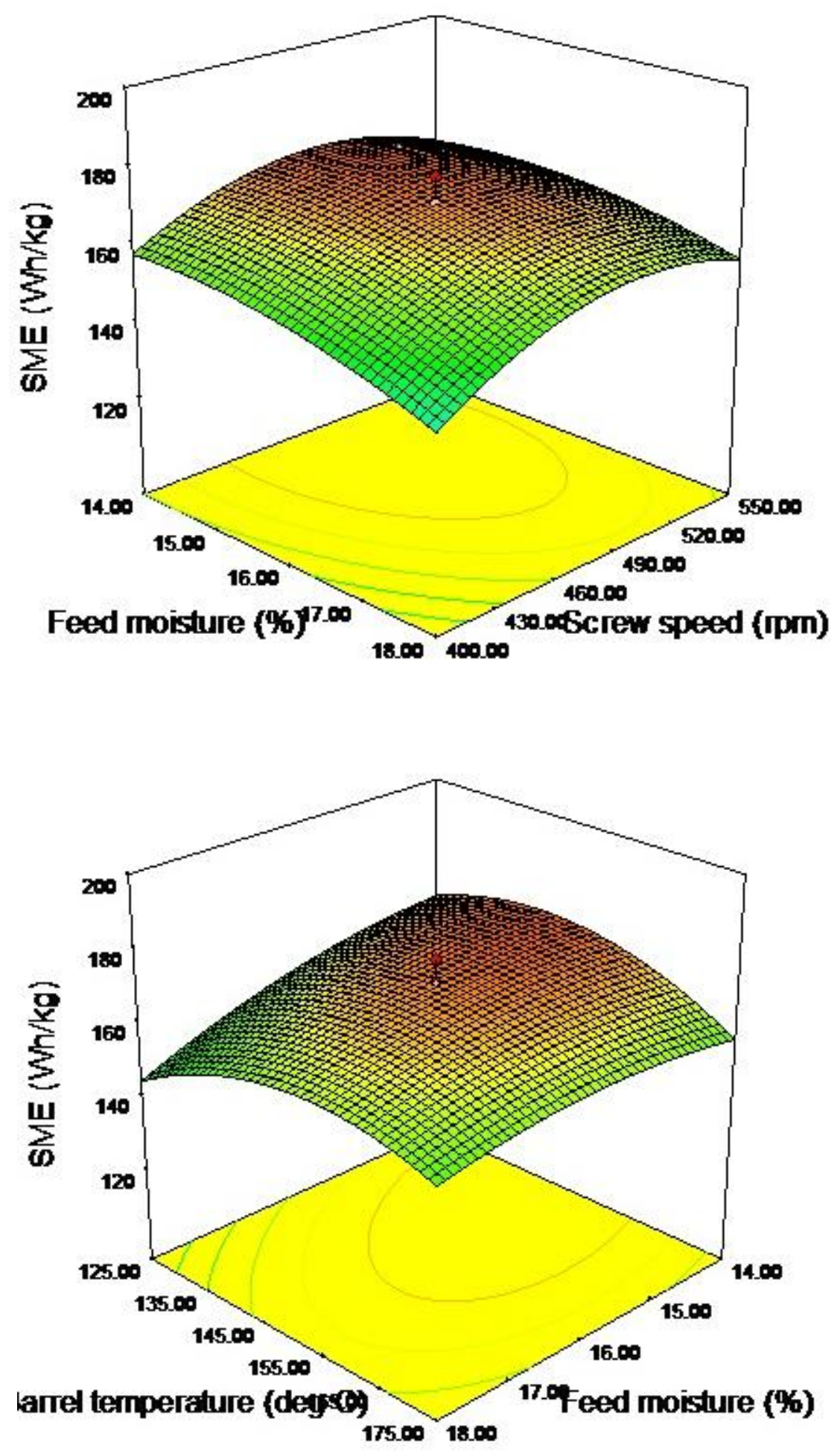
Fig.3 a, b Effect of extrusion variables on bulk density
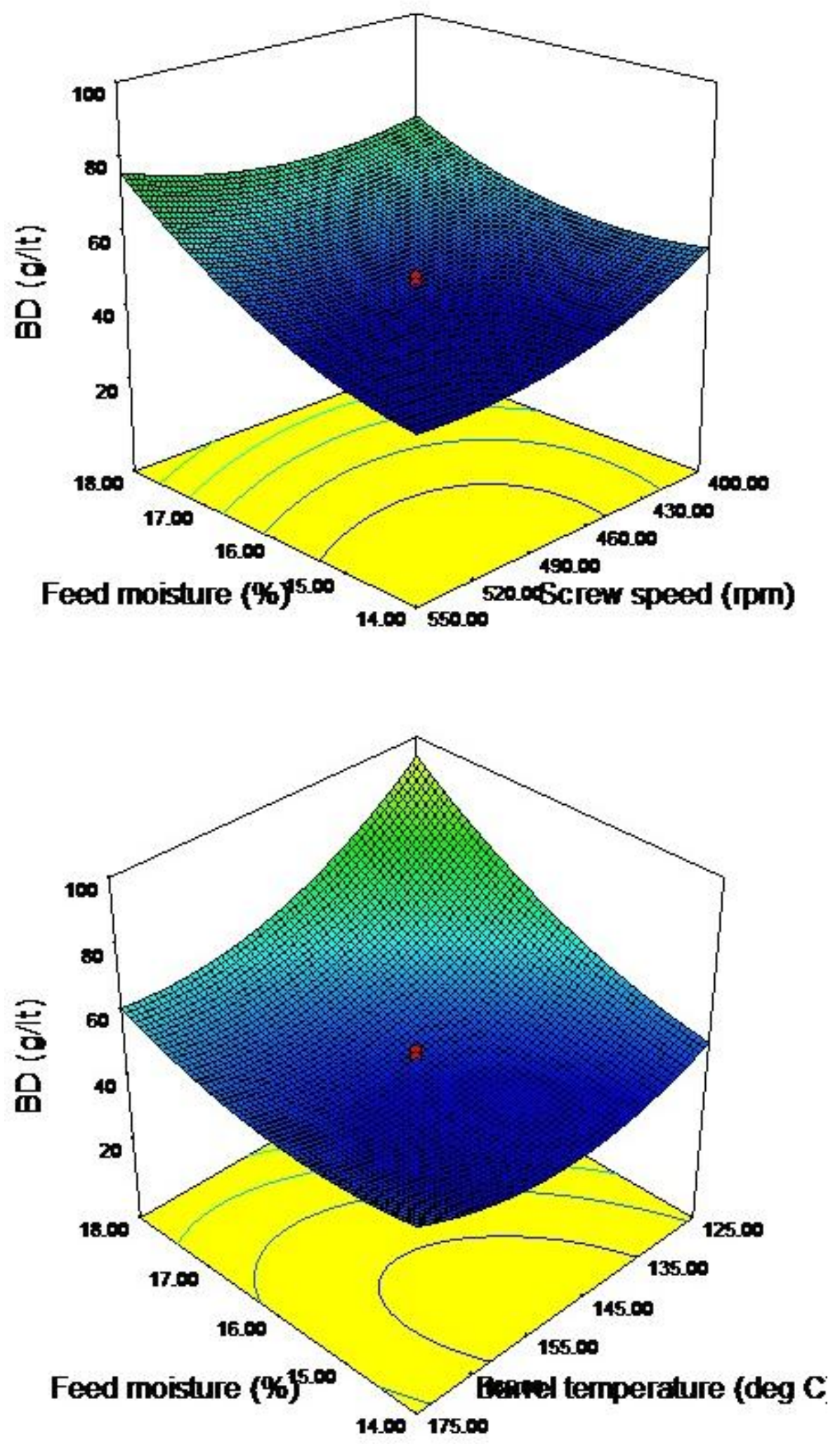
Fig.4 a, b Effect of extrusion variables on expansion ratio
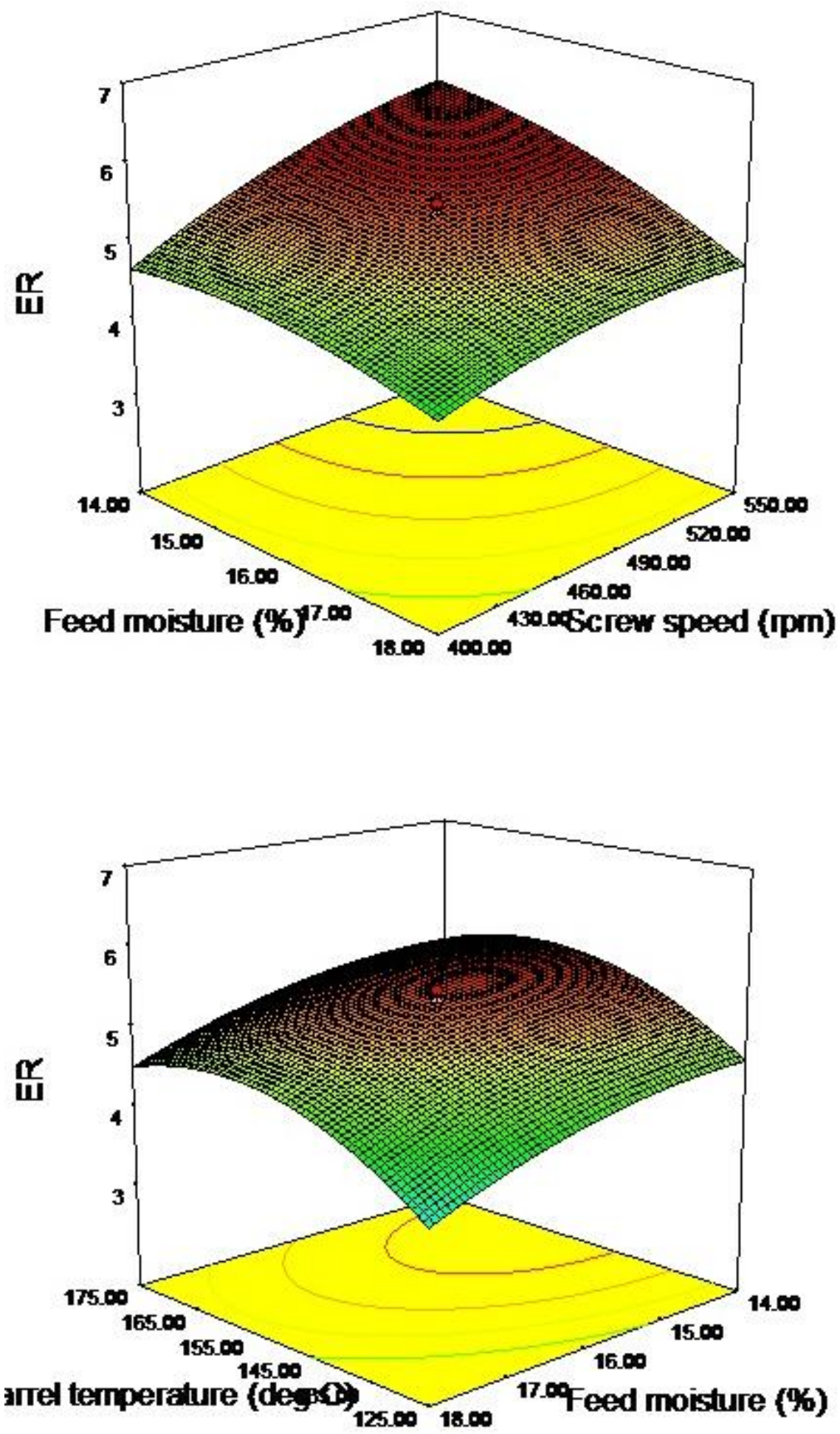
Fig.5 a, b Effect of extrusion variables on water absorption index
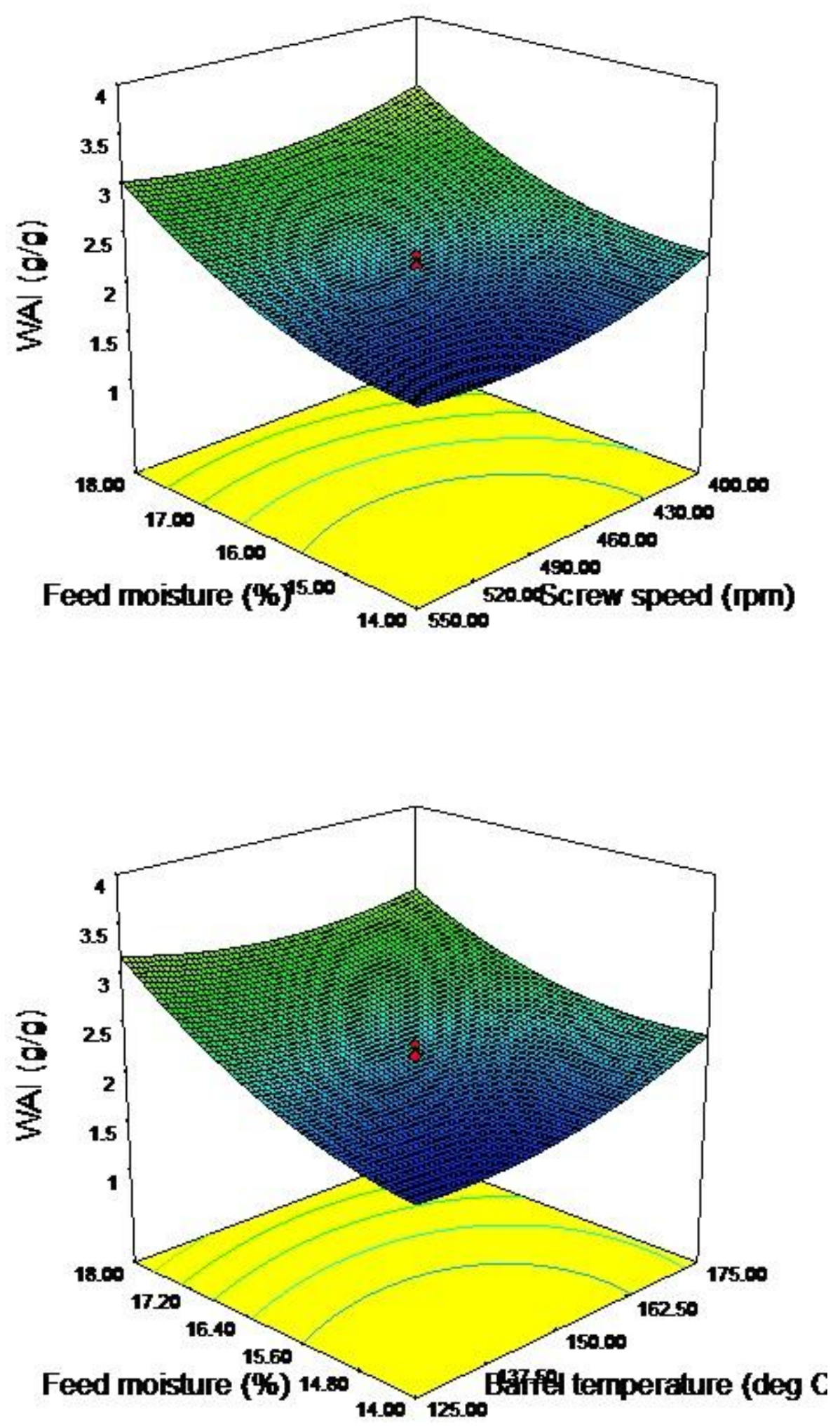
Fig.6 a, b Effect of extrusion variables on water solubility index
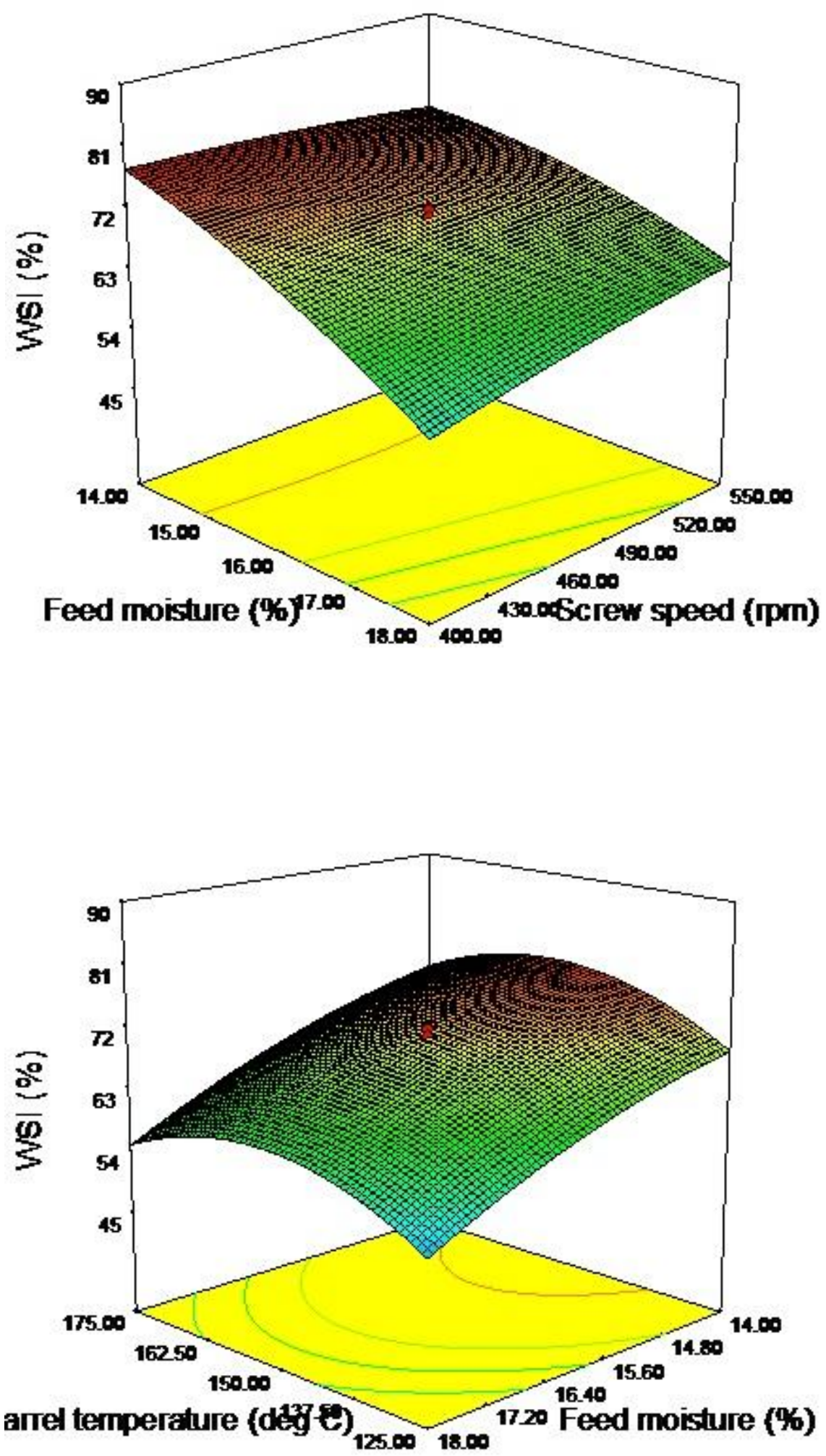
Fig.7 a, b Effect of extrusion variables on degree of gelatinization
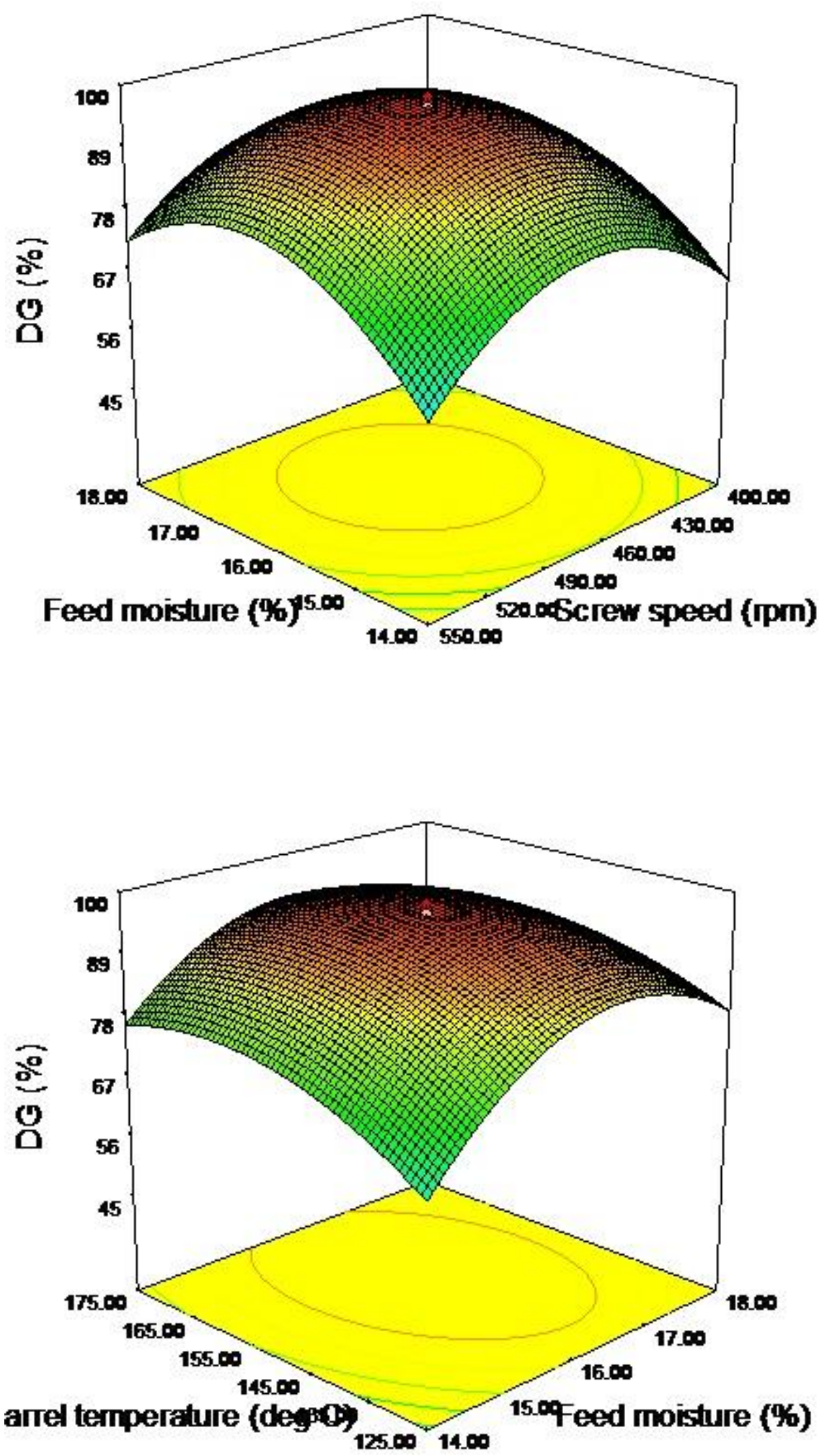
Fig.8 a, b Effect of extrusion variables on in-vitro starch digestibility
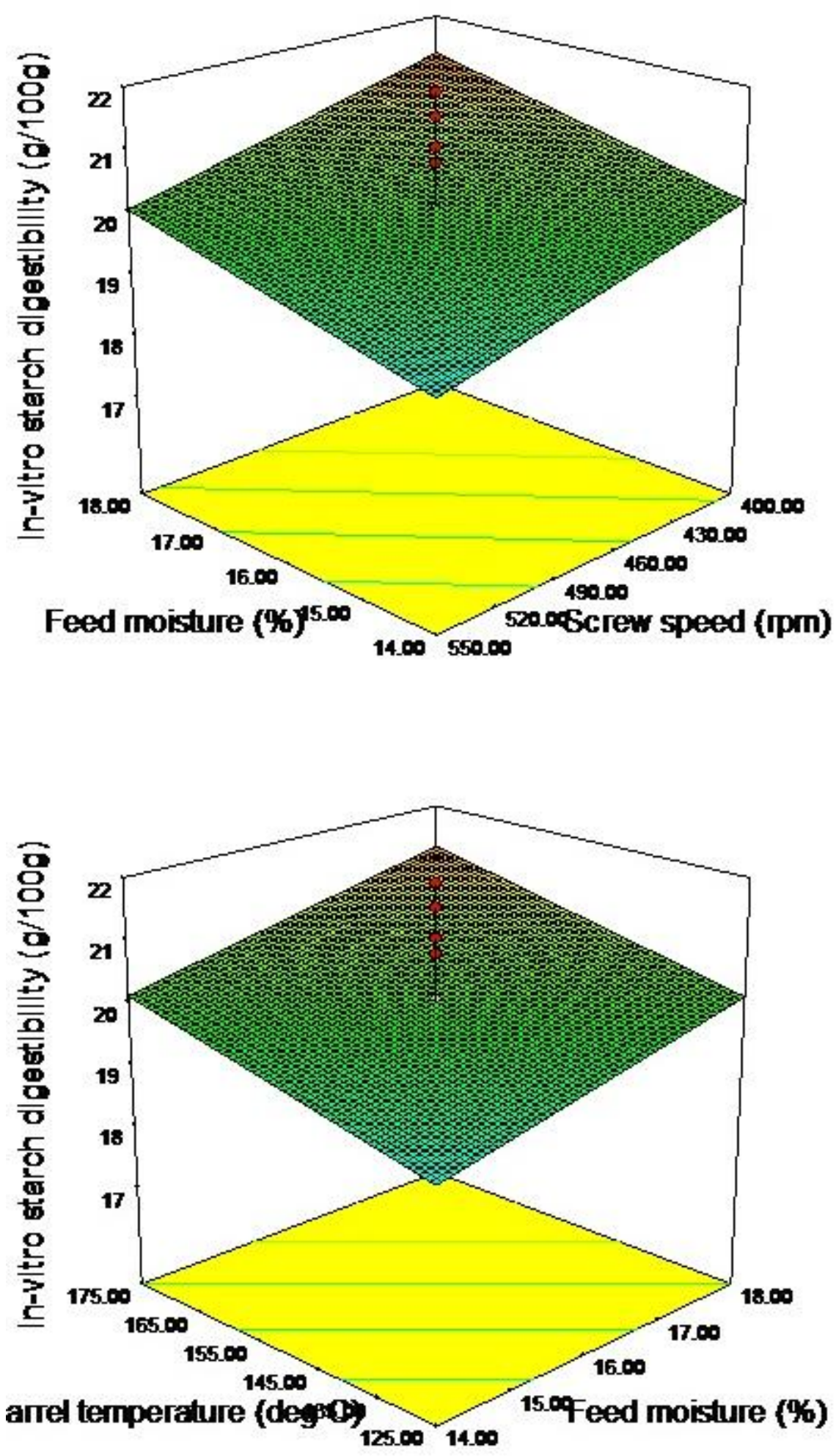
Fig.9 (a, b) Overlaid contour plots for the optimum extrusion conditions of modified corn starch processed by a twin-screw extruder. Shaded area represents optimised conditions that were obtained by superimposing contours of different product responses

\section{DesignExpenta Silmare}

\section{Oreatay Phat}

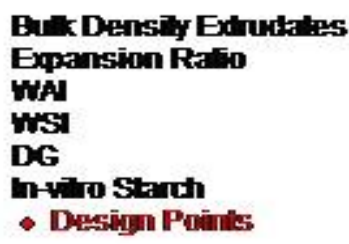

X1 = A- 10ishe X2 = G Temperalar

Anhal Factio B. Scraw speet = 400.01
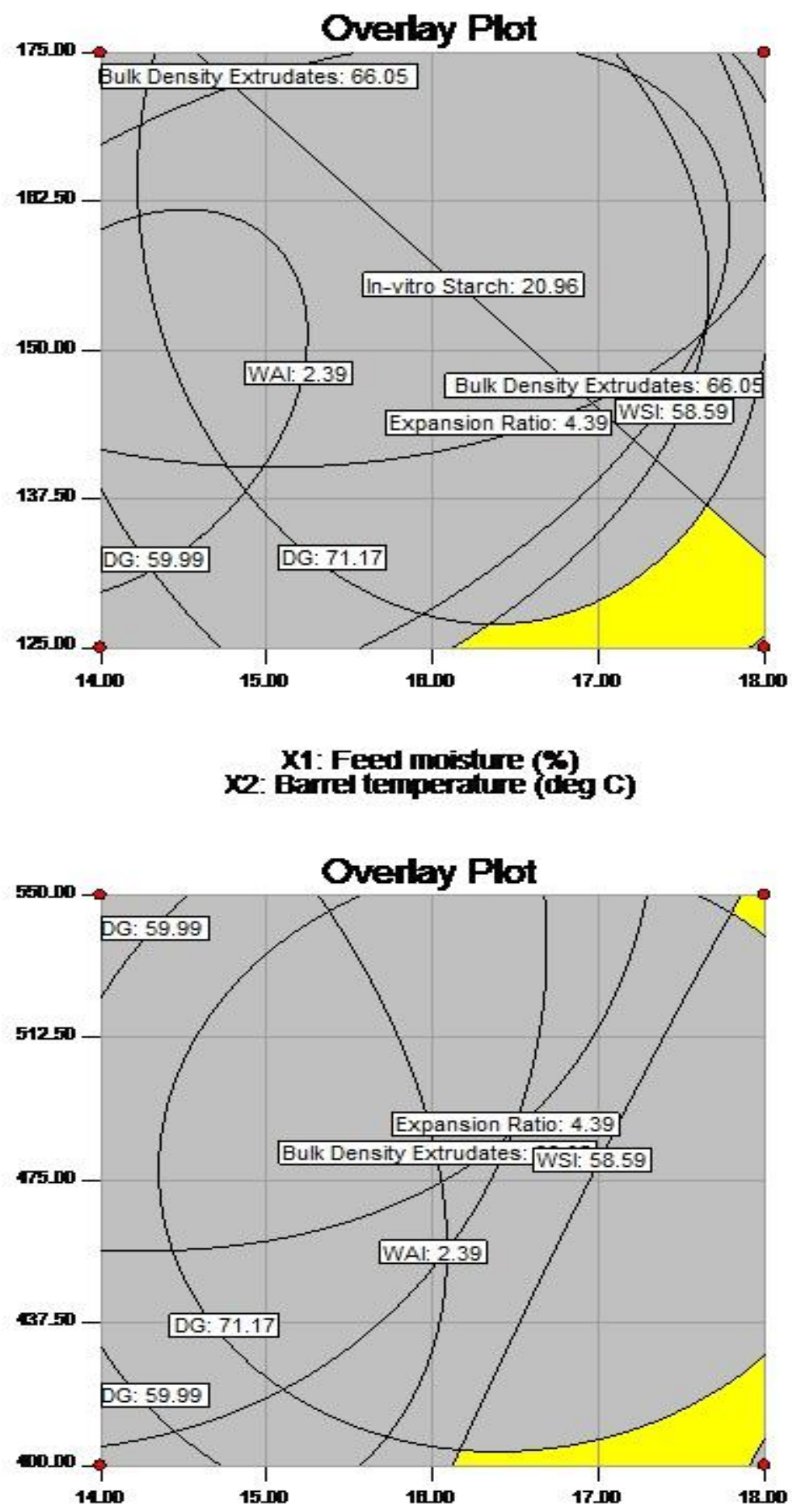

X1: Feed moisture (\%)

XZ: Screw speed (rpm)

X2: Barred temperature (deg C)

\section{Desing-Expens Sn}

\section{Oreikay Pun}

But Densily Exhukates Expansion Ratio WA

USI

DG

h-vino Standh

- Dessigign Puániles

X1 = A: Hoishne

X2 = B: Sorew speet

\section{Acheal Factio}

C. Temperalure $=125.00$ 
Fig.10

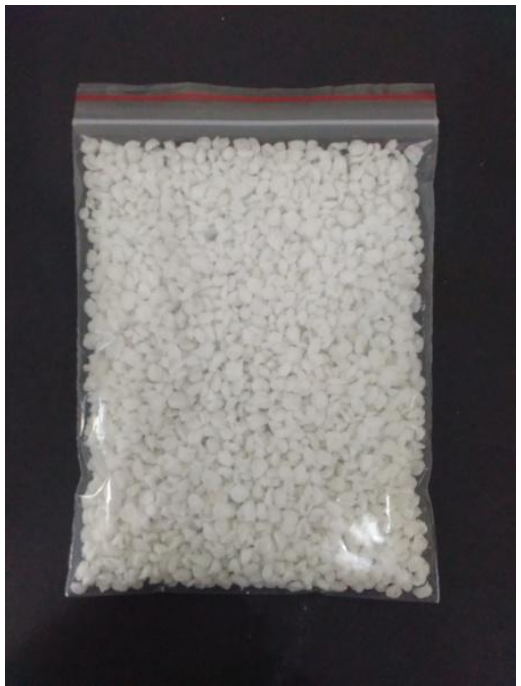

(a) Corn starch extrudates processed at optimised extrusion conditions.

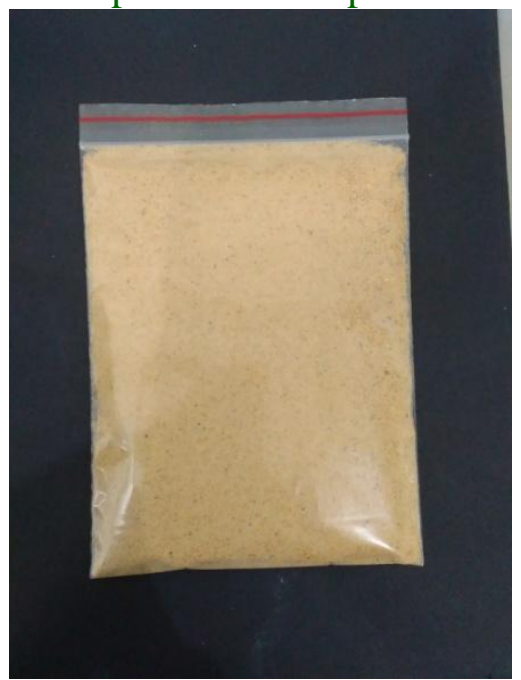

(b) Instant tomato soup mix

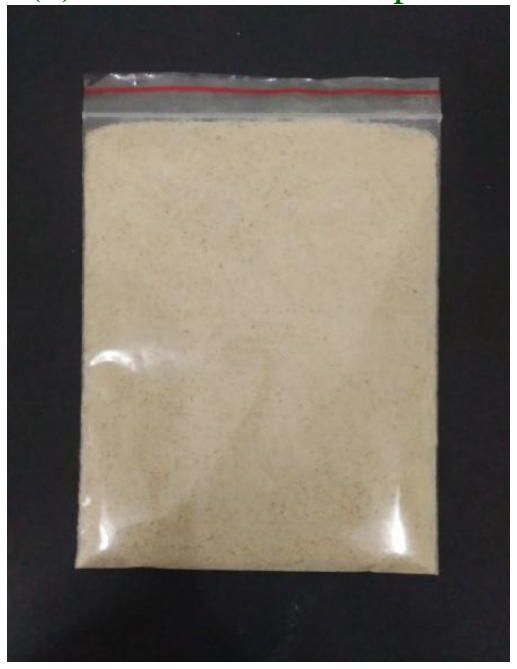

(c) Instant mushroom soup mix 
The WSI values of corn starch extrudates varied between $47.12 \%$ and $78.18 \%$ (Table $2)$. From the regression estimates, linear effects of feed moisture, screw speed and barrel temperature; and quadratic effect of feed moisture and barrel temperature on WSI were significant $(\mathrm{P}<0.01)$ (Table 3$)$. The feed moisture $\mathrm{x}$ screw speed and screw speed $\mathrm{x}$ barrel temperature interaction effects were also significant $(\mathrm{P}<0.01)$. The observed WSI values for corn starch extrudates were higher than extruded rice flour and potato-based snack extrudates (Ding et al., 2005; Singh et al., 2015). WSI increased with increasing barrel temperature and screw speed and decreased by increasing feed moisture (Fig. $6 a, b)$. Similar effects of feed moisture, screw speed and barrel temperature on WSI have been previously reported for rice-, maize- and millet flour-based extrudates (Suksomboon et al., 2011; Joshi et al., 2014; Rashid et al., 2015). It could be expected that higher feed moisture would reduce viscosity, decrease shearing effect and reduce the degree of dextrinisation of starch polymers resulting in decreased WSI. Increased feed moisture reduced the friction of melted dough with screw body and internal barrel surface resulted in minimum damaged starch granules and thus decreased WSI of extrudate. High temperature caused starch degradation resulting into more water soluble carbohydrates that causes increased WSI (Sacchetti et al., 2004). However, harsh extrusion conditions (high temperature, high screw speed and low feed moisture) caused more degradation and dextrinisation of starch polymer resulting in an increased WSI of extruded product. This phenomenon is occurred as a result of the higher mechanical shear at high screw speed which increased fragmentation of starch into small molecules during extrusion cooking at low feed moisture and high temperature (Hagenimana et al., 2006). High WSI is an indicator of good starch digestibility (Hoan et al., 2010) as it implies the extent of gelatinization and dextrinization.

\section{Degree of gelatinisation (DG)}

Gelatinization is the collapse (disruption) of crystalline order within the starch granules manifested to irreversible changes in properties such as granular swelling, native crystalline melting, pasting, loss of optical birefringence, uncoiling and dissociation of double helices, and starch solubilization (Singh, 2003). Degree of gelatinized starch gives the extent of modification that occurred in the starch granules during extrusion and extent of gelatinization depends upon feed moisture, screw speed and barrel temperature during extrusion processing. The DG of corn starch extrudates ranged from $48.48 \%$ to $97.97 \%$ (Table 2). The regression coefficients for linear effects of feed moisture and barrel temperature; quadratic effects of feed moisture, screw speed, barrel temperature and interaction effects of feed moisture $\mathrm{x}$ barrel temperature and screw speed $\mathrm{x}$ barrel temperature for $\mathrm{DG}$ were significant $(\mathrm{P}<$ 0.01). The interaction effect of feed moisture $\mathrm{x}$ screw speed was also found out to be significant $(\mathrm{P}<0.05)$ (Table 3$)$. The $\mathrm{DG}$ values in the current study were similar to extruded barley flour and starch-based extrudates (Altan et al., 2009; Kraus et al., 2014). Feed moisture and barrel temperature showed a positive correlation with DG, whereas screw speed revealed a negative correlation (Figure 7a, b). The trends obtained for the effect of feed moisture, screw speed and barrel temperature on DG in the current study were similar to the trends obtained by other researchers (Davis and Arnold, 1995; Ding et al., 2005). It could be suggested that increasing the feed moisture in the dough would increase both granule swelling and amylose leaching and thus starch gelatinization at higher barrel temperature. Higher extrusion temperature may provide a 
faster transfer of water into the interior of starch molecules that facilitates melting of starch granules consequently increasing gelatinisation. It could be expected that at higher temperature hydrogen bonds would be broken thus more amylose would be released resulting in an increased DG (Ibanoglu et al., 1996). The higher the screw speed, the lower the DG. It can be due to decrease in the retention time of sample in the extruder at higher screw speed, which resulted in the less degree of starch gelatinization. Sacchetti et al., (2004) suggested that the reduction of starch gelatinization with higher screw speed may be because of the considerable dextrinization occurred at high shear. Ratnayake and Jackson (2006) observed similar findings during gelatinization and solubility of corn starch during heating in excess water. DG determines the ratio of gelatinised (digestible) starch to the total starch of the sample; thus, it could be used as an indicator of starch digestibility. Extruded products with high DG are favourable for development of instant foods (Hoan et al., 2010).

\section{In vitro starch digestibility (SD)}

In vitro starch digestibility can be determined from the reducing sugar release during the enzymatic hydrolysis of foods. Swelling and dispersion of starch molecules during gelatinization makes them accessible to digestive enzymes. Thus degree of gelatinization has direct impact on starch digestibility. Immunological method of determining starch digestibility is expensive and time consuming therefore the use of in vitro methods would be both economical and easy to access. The values of In vitro starch digestibility for corn starch extrudates ranged from 17.8 to $22 \mathrm{~g} / 100 \mathrm{~g}$ (Table 2). The in vitro starch digestibility for corn starch extrudates was found out be lower than extruded barley flour and extruded rice samples (Altan et al.,
2009; Guha, 1997). The linear regression coefficients of feed moisture, screw speed and barrel temperature for In vitro starch digestibility were significant $(\mathrm{P}<0.05)$ (Table $3)$. The starch digestibility was found to increase with an increase in barrel temperature and feed moisture (Fig. 8a, b) which could be attributed to increased gelatinization.

During extrusion cooking, high-temperature and high-shear forces cause a high degree of starch gelatinization, increasing the susceptibility of starch to enzyme hydrolysis (Holm et al., 1985), therefore, low levels of resistant starch were expected. Bishnoi and Khetarpaul 1993 found that the degree of starch gelatinisation in thermally treated samples is higher than in untreated ones and it is thus more readily hydrolysed. Fragmentation of starch during extrusion makes starch more susceptible to enzymatic hydrolysis thus improve digestibility (Doublier et al., 1986). Similar results found by Alonso et al., (2000) in pea starch.

\section{Optimization of experiment}

On the basis of sensory evaluation, five samples of optimum functional characteristics were selected. For graphical optimization, minimum and maximum range for each response of selected samples was applied that is BD (66.05- 111.51), ER (3.02- 4.39), WAI (2.39- 3.79), WSI (47.12- 58.59), DG (59.9971.17) and SD (17.80- 20.96). SME was not included in optimization process as it is an operation parameter. Overlay contour plots were developed by superimposing the contour graphs of selected responses using DesignExpert software. The optimized extrusion conditions obtained for corn starch extrudates for soup preparation were feed moisture (16.13-18\%), screw speed (400-429 and 539$550 \mathrm{rpm})$ and barrel temperature $\left(125-137^{\circ} \mathrm{C}\right)$ as shown in Figure 9a, b. 
Proximate composition of the instant vegetable soup mix

Optimised extrusion conditions were applied to produce the modified corn starch (Fig. 10a). Instant tomato and mushroom soup mixes (Fig. 10b, c) were prepared using the recommended levels of ingredients based on sensory evaluation values, that is modified corn starch 50\%, tomato/mushroom powder $17.9 \%$, skim milk powder $10 \%$, powdered sugar $10 \%$, salt $10 \%$, black pepper $2 \%$ and citric acid $0.1 \%$. The proximate composition of the final instant vegetable soup mix is moisture $8.05 \%$ and $8.57 \%$, protein $5.80 \%$ and $6.42 \%$, fat $2.25 \%$ and $2.27 \%$, fiber $3.81 \%$ and $5.60 \%$, minerals 2.03 and $1.75 \%$ and carbohydrates $70.83 \%$ and $69.71 \%$ with energy density 327 and $325 \mathrm{kcal}$ per $100 \mathrm{~g}$ for tomato and mushroom soup respectively. Degree of gelatinization was higher in the final product (tomato soup 65\% and mushroom soup 62\%) than in the raw corn starch (9.98\%). Moreover, in vitro starch digestibility was 16.44 and $15.92 \mathrm{~g} / 100 \mathrm{~g}$ for tomato and mushroom soup mixes whereas it was $1.64 \mathrm{~g} / 100 \mathrm{~g}$ in the raw corn starch. During extrusion cooking, starch is gelatinised, the crystalline structure is lost, the glucoside bonds are broken, and the molecules become more easily accessible to enzymatic degradation resulting in an increased solubility and digestibility (RuizRuiz et al., 2008).

Extrusion process optimization using response surface methodology revealed significant effect of extrusion variables (feed moisture, screw speed and barrel temperature) on functional properties of modified corn starch prepared by twin screw extruder. It could be concluded that all extrusion variables have linear significant effect on all product responses (SME, BD, ER, WAI, WSI, DG; P < 0.01) (SD; P < 0.05). The product responses were dependent mainly on the feed moisture. Feed moisture had negative effect on SME, ER and WSI while it had positive effect on BD and WAI and DG and SD. Barrel temperature had negative effect on SME, BD and showed positive relation with ER, WAI, WSI, DG and SD. Screw speed revealed positive relation with SME, ER and WSI whereas negative relation with $\mathrm{BD}$, WAI, DG and SD. Optimum extrusion conditions, established using RSM, for modification of corn starch to prepare instant vegetable soup mix were feed moisture of $16.13-18 \%$, screw speed of 400-429 rpm and 539-550 rpm and barrel temperature of 125$137{ }^{\circ} \mathrm{C}$. It could be suggested that nutritious and acceptable instant vegetable soup mixes can be developed with high solubility and digestibility using extrusion technology.

\section{References}

Abdel-Haleem, A. M. H. and Omran, A. A. 2014. Preparation of dried vegetarian soup supplemented with some legumes. Food and Nutrition Sciences. 5: 2274-85.

Adegoke, B. H., Adedayo, A. E. and Temilola, D. 2016. Proximate, phytochemical and sensory quality of instant pepper soup mix. J Culinary Sci Technol. 14(1): 59-74.

Ali, Y., Hanna, M. A. and Chinnawamy, R. 1996. Expansion characteristics of extruded corn grits. LWT-Food Sci Technol 29: 702-707.

Alonso, R., Grant, G., Dewey, P. and Marzo, F. 2000. Nutritional assessment in vitro and in vivo of raw and extruded peas (Pisum sativum L.). Journal of Agricultural and Food Chemistry. 48: 2286-2290.

Altan, A., McCarthy, K.L. and Maskan, M. 2008. Evaluation of snack foods from barleytomato pomace blends by extrusion processing. Journal of Food Engineering. 84: 231-242.

Altan, A., McCarthy, K.L. and Maskan, M. 2009. Effect of extrusion cooking on functional properties and in vitro starch digestibility of barley-based extrudates from fruit and vegetable by-products. Journal of Food Science. 74: 77-86.

Anton, A. A., Fulcher, R. G. and Arntfield, S. D. 
2009. Physical and nutritional impact of fortification of corn starch-based extruded snacks with common bean (Phaseolus vulgaris L.) flour: Effects of bean addition and extrusion cooking. Food Chemistry. 113: 989-996.

AOAC. 2006. Official Methods of Analysis, 18th edn. Washington, DC: Association of Official Analytical Chemists.

Asare, E. K., Sefa-Dedah, S., Sakyi-Dawson, E. and Afoakwa, E. O. 2004. Application of response surface methodology for studying the product characteristics of extruded ricecowpea-groundnut blends. Inter J Food Sci Nutr. 55: 431-439.

Balasubramanian, S., Kaur, J. and Singh, D. 2014. Optimization of weaning mix based on malted and extruded pearl millet and barley. Journal of Food Science and Technology. 51: 682-690.

Banerjee, G., Car, S., Scott-Craig, J.S., Borrusch, M.S., Aslam, N. and Walton, J.D. 2010. Synthetic enzyme mixtures for biomass deconstruction: production and optimization of a core set. Biotechnology and Bioengineering. 106: 707-720.

Bernfeld, P. 1955. Amylases, $\alpha$ and $\beta$. In Methods in Enzymology, Vol. 1, (S. P. Colowick and N. 0. Kaplan, eds.). Academic Press, New York.

Bishnoi, S., and Khetarpaul, N. 1993. Effect of domestic processing and cooking methods on invitro starch digestibility of dierent pea cultivars (Pisum sativum). Food Chem. 47: 177-182.

Brummera, T., Meuserb, F., Lengerichc, B. Van, and Niemannd, C. 2002. Effect of extrusion cooking on molecular parameters of corn starch. Starch. 54: 1-8.

Cai, W. and Diosady, L. L. 1993. Model for gelatinization of wheat starch in a twinscrew extruder. J Food Sci. 58: 872-875.

Chevanan, N., Rosentrater, K. A. and Muthukumarappan, K. 2007. Twin screw extrusion processing of feed blends containing distiller's dried grains with solubles (DDGS). Cereal Chem. 84: 427436.

Chinnaswamy, R. and Hanna, M. A. 1990. Macromolecular and functional properties of native and extrusion cooked corn starch.
Cereal Chem. 67: 490-499.

Davis, D. A. and Arnold, C. R. 1995. Effects of two extrusion processing conditions on the digestibility of four cereal grains for Penaeus vannamei. Aquaculture. 133: 287294.

Ding, Q., Ainsworth, P., Tucker, G. and Marson, H. 2005. The effect of extrusion conditions on the physicochemical properties and sensory characteristics of rice-based expanded snacks. Journal of Food Engineering. 66: 283-289.

Doublier, J. L., Colonna, P. and Mercier, C. 1986. Extrusion cooking and drum drying of wheat-starch. Rheological characterization of starch pastes. Cereal Chem. 63: 240-246.

Guha, M., Ali, S. Z. and Bhattacharya, S. 1997. Twin screw extrusion of rice flour without a die: Effect of barrel temperature and screw speed on extrusion and extrudate characteristics. J Food Eng. 32: 251-267.

Gulati, P., Weier, S.A., Santra, D., Subbiah, J. and Rose, D.J. 2016. Effects of feed moisture and extruder screw speed and temperature on physical characteristics and antioxidant activity of extruded proso millet (Panicum miliaceum) flour. International Journal of Food Science and Technology. 51: 114-122.

Guy, R. 2001. Extrusion Cooking: Technologies and Applications. Woodhead: Cambridge, U.K. pp. 89.

Hagenimana, A., Ding, X. and Fang, T. 2006. Evaluation of rice flour modified by extrusion cooking. Journal of Cereal Science. 43: 38-46.

Hoan, N. V., Mouquet-Rivier, C. and Treche, S. 2010. Effects of starch, lipid and moisture contents on extrusion behavior and extrudate characteristics of rice-based blends prepared with a verylow- cost extruder. Journal of Food Process Engineering. 33: 519-539.

Holm, J., Bjorck, I., Asp, N. G., Sjoberg, L. B. and Lundquists, I. 1985. Starch availability in vitro and in vivo after flaking, steamcooking and popping of wheat. Journal of Cereal Science. 3: 193-206.

Ibanoglu, S., Ainsworth, P. and Hayes, G. D. 1996. Extrusion of tarhana: effect of operating variables on starch gelatinization. Food Chemistry. 57: 541-544. 
Joshi, S. M. R., Bera, M. B. and Panesar, P.S. 2014. Extrusion cooking of maize/spirulina mixture: factors affecting expanded product characteristics and sensory quality. Journal of Food Processing and Preservation. 38: 655-664.

Kanias, G. D. 1991. Nutrient and other trace elements in instant soups. Journal of Radioanalytical and Nuclear Chemistry. 151 (2): 245-254.

Karthikeyan, M. S., Divakar, S., Ukkuru, M., Nirmala, P. C. and Kumari, M. K. S. 2015. Development of instant soup mix (ISM) from banana peel. International Journal of Current Research. 7(8):19260-263.

Kaur, A., Kaur, S., Singh, M., Singh, N., Shevkani, K. and Singh, B. 2015. Effect of banana flour, screw speed and temperature on extrusion behaviour of corn extrudates. $J$ Fd Sci Technol. 52: 4276-4285.

Kaur, G. 2013. Modified flours by htst processing: characterization, thermal properties and functionality. Ph.D. Thesis, Punjab Agricultural University, Ludhiana, India.

Kebede, L., Worku, S., Bultosa, G. and Ytneberek, S. 2010. Effect of extrusion operating conditions on the physical and sensory properties of tef (Eragrastis tef [Zucc.] Trotter) flour extrudates. European J Agric Sci Technol. 1: 27-38.

Kokini, J. L., Lai, L. and Chedid, L. L. 1992. Effect of starch structure on rheological properties. Food Technol. 46: 124-139.

Kraus, S., Enke, N., Gaukel, V. and Schuchmann, H. P. 2014. Influence of degree of gelatinization on expansion of extruded, starchbased pellets during microwave vacuum processing. Journal of Food Process Engineering. 37: 220-228.

Lin, Y. H., Yeh, C. S. and Lu, S. 2003. Extrusion Processing of Rice-Based Breakfast Cereals Enhanced with Tocopherol from a Chinese Medical Plant. Cereal Chem. 80: 491-494.

Meng, X., Threinen, D., Hansen, M. and Driedger, D. 2010. Effects of extrusion conditions on system parameters and physical properties of a chickpea flour-based snack. Food Research International. 43: 650-658.

Mercier, C. and Fiellet, P. 1975. Modification of carbohydrate components by extrusion cooking of cereal products. Cereal Chem.
52: 283-297.

Onyango, C., Henle, T., Zeims, A., Hofmann, T. and Ble, T. 2004. Effect of extrusion variables on fermented maize- finger millet blend in the production of uji. LWT Food Sci and Technol. 37: 409-415.

Pandey, M. C., Harilal, P. T., Mallika, M., Jayathilakan, K., Srihari, K. A., Radhakrishna, K. and Bawa, A. S. 2009. Freeze dried rabri powder: Product development and quality evaluation. J Food Sci Technol. 46: 46-49.

Pathania, S., Singh, B., Sharma, S., Sharma, V. and Singla, S. 2013. Optimization of extrusion processing conditions for preparation of an instant grain base for use in weaning foods. Int J Engg Res Appl. 3: 1040-1049.

Patil, R. T., Berrios, J. A. and Swansons, B. G. 2007. Evaluation of methods for expansion properties of legume extrudates. Applied Engg Agric. 23: 777-783.

Rashid, S., Rakha, A., Anjum, F.M., Ahmed, W. and Sohail, M. 2015. Effects of extrusion cooking on the dietary fibre content and Water Solubility Index of wheat bran extrudates. International Journal of Food Science and Technology. 50: 1533-1537.

Ratnayake, W. S. and Jackson, D. S. 2006. Gelatinization and solubility of corn starch during heating in excess water: New Insights. Faculty Publications in Food Sci Technol- University of Nebraska- Lincoln, p: 118.

Rodriguez-Miranda, J., Ruiz Lopez, I. I., Herman Lara, E and Vivar-Vera, M. A. 2011. Development of extruded snacks using taro (Colocasia esculanta) and nixtermalized maize (Zea mays) flour blends. LWT Food Sci Technol. 44: 673-680.

Ruiz-Ruiz, J., Martinez-Ayala, A., Drago, S., Gonzalez, R., Betancur- Ancona, D. and Chel-Guerrero, L. 2008. Extrusion of a hard-to-cook bean (Phaseolus vulgaris L.) and quality protein maize (Zea mays L.) flour blend. LWT - Food Science and Technology. 41: 1799-1807.

Sacchetti, G., Pinnavaia, G. G., Guidolin, E. and Dalla Rosa, M. 2004. Effects of extrusion temperature and feed composition on the functional, physical and sensory properties 
of chestnut and rice flour based snack-like products. Food Res Int. 37: 527-534.

Seker, M. 2005. Selected properties of nature or modified maize starch/soy protein mixtures extruded at varying screw speed. J Sci Food Agric. 85: 1161-1165.

Singh, B., Rachna, Hussain, S.Z. and Sharma, S. 2015. Response surface analysis and process optimization of twin screw extrusion cooking of potato-based snacks. Journal of Food Processing and Preservation. 39: 270-281.

Singh, N., Singh, J., Kaur, L., Sodhi, N. S. and Gill, B. S. 2003. Morphological, thermal and rheological properties of starches from different botanical sources. Food Chemistry. 81: 219-231.

Singh, R. K. R., Majumdar, R. K. and Venkateshwarlu, G. 2014. Optimum extrusion-cooking conditions for improving physical properties of fish-cereal based snacks by response surface methodology. Journal of Food Science and Technology. 51: 1827-1836.

Sudharani, N., Hiremath, U. S. and Shivaleela, H. B. 2013. Standardization of ash gourd and amla based instant juice and soup mixes. Global Journal of Biology, Agriculture and Health Sciences. 2(1): 10-19.

Suksomboon, A., Limroongreungrat, K., Sangnark, A., Thititumjariya, K. and Noomhorm, A. 2011. Effect of extrusion conditions on the physicochemical properties of a snack made from purple rice (Hom Nil) and soybean flour blend. International Journal of Food Science and Technology. 46: 201-208.

Tamlurkar, V. 2006. Role of Instant Foods in the Catering Industry. For: Faculty-Column in www.indianmba.com.

Wadikar, D. D., Madhura, C. V. and Premavalli, K. S. 2011. Development of ginger based appetizer in the form of ready to reconstitute mix and ready to drink beverage. Int J Food Sci Nutr. 62(4): 404409.

Wadikar, D. D., Majumdar, T. K., Nanjappa, C., Premavalli, K. S. and Bawa, A. S. 2008 Development of pepper based shelf stable appetizers by Response surface methodology (RSM). LWT Food Sci Technol. 41: 1400-11.

Yagci, S. and Gogus, F. 2008. Response surface methodology for evaluation of physical and functional properties of extruded snack foods developed from food-by-products. $J$ Food Eng. 86: 122-132.

Yuan, Y., Gao, Y., Mao, L. and Zhao, J. 2008. Optimisation of conditions for the preparation of bcarotene nanoemulsions using response surface methodology. Food Chemistry. 107, 1300-1306.

\section{How to cite this article:}

Neeraj Gandhi, Baljit Singh, Savita Sharma and Swati Kapoor. 2018. Extrusion Process Optimization of Corn Starch to Develop Instant Vegetable Soup Mix. Int.J.Curr.Microbiol.App.Sci. 7(02): 2886-2910. doi: https://doi.org/10.20546/ijcmas.2018.702.352 